\title{
REHYDRATION KINETICS OF DEHYDRATED BERRIES
}

\author{
Ígor H. de M. R. Ciolin ${ }^{1,2}$, Camila W. Antunes ${ }^{1}$, Daiane C. Lenhard ${ }^{1}$, Carolina C. Garcia ${ }^{\text {* }}$
}

${ }^{1 *}$ Corresponding author. Academic Department of Food, Federal University of Technology - Paraná, Campus Medianeira/ Medianeira - PR, Brasil. Email: carolinacgarcia@utfpr.edu.br | ORCID ID: https://orcid.org/0000-0002-4497-2026

\section{KEYWORDS}

Blueberry, cranberry, diffusivity, mathematical modeling, Vaccinium sp.

\begin{abstract}
Cranberries and blueberries are small fruits known for their antioxidant properties. However, due to their high water content and short shelf life, they are generally marketed as dehydrated berries. The present work aimed to model the rehydration of dehydrated berries. Rehydration tests were conducted at 7 and $29^{\circ} \mathrm{C}$ using milk as a solvent and at 7 , 29 , and $45^{\circ} \mathrm{C}$ when the solvent was water. The mass gain was assessed at different intervals, and the experimental data were fitted to the Fick model considering the berries as spheres. Six empirical/semi-empirical models describing the diffusion of water during drying were used to predict the rehydration process. Fick's law satisfactorily represented the data, and the highest diffusion coefficients were found when the berries were rehydrated in water at $45^{\circ} \mathrm{C}$. Rehydration of berries in milk resulted in nutrient gain as different diffusive flows occurred during the process. The use of empirical models to predict the operating time of the rehydration processes allows flexibility as such models are mathematically simpler than the Fick model. Diffusivity is essential for the design/construction of equipment, and/or process optimization and implementation.
\end{abstract}

\section{INTRODUCTION}

The cranberry is a false berry with an intense red color and a very pronounced acid taste. In 2018, the annual global cranberry production surpassed 722 thousand tons, of which the American continents were responsible for more than 95\%, and the USA, Canada, and Chile were the leading producers of this fruit. The blueberry has a characteristic bittersweet taste, a bluish-purple color, and many seeds in its interior. In 2018, more than 680 thousand tons of blueberries were produced worldwide, and Canada was the major producer (FAOSTAT, 2020).

Berry fruits, such as cranberries, bilberries, lowbush blueberries, and blueberries, are rich sources of bioactive compounds, mostly polyphenolics, as well as polysaccharides, carotenoids, ascorbic acid, and others (Gramza-Michałowska et al., 2017). Numerous healthpromoting properties of berries have been identified, such as in reduction of cancer, cardiovascular and neurological diseases as well as anti-inflammatory, antibacterial, antiallergic, anti-hypertensive, antiviral and wound-healing effects (Ballesteros et al., 2017; Alvarez-Suarez et al., 2016). Phenolic compounds, present in many fruits and vegetables, have been studied extensively for their high antioxidant power because they are capable of increasing resistance to oxidative damage caused by free radicals generated in the human body (Ho et al., 2020).

Although they are beneficial to health, most berries, such as cranberries, blueberries, and raspberries, are traditionally grown in areas with cold climates, such as swamps and coniferous forests (Oszmiański et al., 2015), and must therefore be harvested during a specific period, which is one of the factors limiting their consumption. The climate over most of Brazil is typical of a tropical country, which limits the harvest of these fruits to the southern region, restricting their production and consumption (Silveira et al., 2007).

The high moisture content of berries is also a limiting factor in their storage shelf life, which is only a few days. Some preservation methods, such as drying, have been used to increase the shelf life and the possibility of continuous commercialization of food products. Drying increases the shelf life of a dehydrated product, as it reduces its water activity, stabilizing/decreasing the microbiological, biochemical, and chemical activity. Dehydration also reduces the cost of transportation and

${ }^{1}$ Academic Department of Food, Federal University of Technology, Campus Medianeira/ Medianeira - PR, Brasil.

${ }^{2}$ Department of Chemical Engineering and Food Engineering - Federal University of Santa Catarina, Florianópolis - SC, Brasil.

Area Editor: Ednilton Tavares de Andrade

Received in: 11-15-2020

Accepted in: 4-26-2021 
storage, due to the weightlessness and compactness it imparts. The dehydration process must guarantee adequate moisture in the dry product for better conservation of the fruit, thus guaranteeing its quality (Rudy et al., 2015; Krokida \& Marinos-Kouris, 2003; Lewicki, 1998).

The preservation of fruits, vegetables, and similar products by dehydration is a major challenge because moisture removal must be carried out so as to minimize damage, thus guaranteeing product quality. In this way, the characteristics of the dehydrated product following rehydration are as close as possible to those of the natural product (Demiray \& Tulek, 2017).

To recover the properties of the fresh product, the dehydrated fruit goes through a complex process of rehydration, which can be considered as a measure of the damage caused by the drying processes and dehydration treatments (Lee et al., 2006). Rehydration is divided into three stages: soaking the dried fruit, swelling the rehydrated fruit, and leaching the soluble compounds. Its purpose is to obtain products that, when reconstituted, present the characteristics of texture and increased volume that render them suitable for consumption (Gökçe Kocabay \& İsmail, 2017; Lee et al., 2006). According to Lee et al. (2006), after the water has filled all the pores, the properties of the fresh product are partially restored.

The study of food rehydration kinetics enables the design of equipment and the optimization of the rehydration process because it considers the speed of water absorption and how it will be affected by variations in processing, indicating how the saturation time can be predicted. Rehydration data provide information on the water transport mechanism used to determine the water diffusion coefficient in products (Demiray \& Tulek, 2017).

Considering the nutritional value of berries, their unique taste and color, and their use in bakery products, while aiming to obtain the necessary data for construction/improvement of equipment and optimization of implemented processes, the present work studied the rehydration kinetics of dehydrated cranberries and blueberries.

\section{MATERIAL AND METHODS}

\section{Raw materials and physicochemical analysis}

Dehydrated cranberries and blueberries were purchased from a market specializing in natural products in the cities of Medianeira and Foz de Iguaçu, state of Paraná, Brazil, in February and September 2016, respectively.

Analyses of moisture content, protein, ash, and water activity were performed in triplicate on dehydrated berries and fruits rehydrated in water and milk, for 45 minutes at room temperature. The operating temperature was selected to produce the lowest energy expenditure. The choice of rehydration time was based on the percent water gained by the berries during rehydration, so that the rehydrated fruit would have similar characteristics to those of fresh ones in the shortest possible processing time. After 45 minutes of processing, the berries showed a mass gain of more than $40 \%$, mainly due to water absorption.

The moisture content of the samples was determined gravimetrically in an oven at $105^{\circ} \mathrm{C}$ until they reached a constant weight, and the ash content was determined in a muffle furnace at $550^{\circ} \mathrm{C}$ until a white residue was obtained, both according to the methodology proposed by the Association of Official Analytical Chemists (AOAC, 2005). To determine the protein content, the Kjedhal method was used, with eight hours of digestion, using $6 \mathrm{~g}$ of catalytic mixture to which was added $25 \mathrm{~mL}$ of concentrated sulfuric acid and $5 \mathrm{~g}$ of sample. For distillation, boric acid, mixed indicator, and $50 \%$ sodium hydroxide were used to neutralize the sample. For titration, $0.1 \mathrm{~N}$ hydrochloric acid was used, and the correction factor for calculating the total protein content was 6.25 (AOAC, 2005). Water activity was determined using Aqualab equipment (AquaLab 4TE, São José dos Campos, SP, Brazil).

\section{Rehydration kinetics}

Berries were rehydrated according to a methodology adapted from Demiray \& Tulek (2017) and Falade \& Abbo (2007), in triplicate, in beakers, using a 1:40 ratio of sample to solvent (water or milk).

Rehydration experiments using milk were carried out at a temperature of $7^{\circ} \mathrm{C} \pm 3^{\circ} \mathrm{C}$, in a domestic refrigerator (Brastemp Frost Free Duplex, Medianeira, PR, Brazil), and at room temperature $\left(29^{\circ} \mathrm{C} \pm 1^{\circ} \mathrm{C}\right)$. Rehydration experiments using water, besides these two temperatures, were also carried out at $45^{\circ} \mathrm{C} \pm 1^{\circ} \mathrm{C}$. Experiments performed at temperatures of 29 and $45^{\circ} \mathrm{C}$ were carried out in BOD incubator chambers (BOD, Cienlab, Campinas, SP, Brazil).

Samples were weighed during rehydration at regular intervals for $30 \mathrm{~h}$. Fruits were carefully removed from the beaker with a lab spatula and gently dried with absorbent paper before weighing. Due to the weighing procedure, after $16 \mathrm{~h}$ of rehydration, it was found that the fruits started to lose small pieces during weighing, resulting in a mass loss. Thus, the mass gain data for the berries were considered for up to $16 \mathrm{~h}$ of processing. Therefore, the equilibrium data were obtained dynamically after $16 \mathrm{~h}$ of rehydration.

\section{Mathematical modeling}

The experimental data for mass gain were fitted to Fick's law (Equation 1) considering berries as spheres and inserting sphericity into the equation (Equation 2), as proposed by Falade \& Abbo (2007) and Hebbar \& Rastogi (2001).

$$
\frac{d X}{d t}=D_{e f f} \frac{\partial^{2} X}{\partial z^{2}}
$$

in which:

$X$ represents moisture, on a dry basis;

$t$, time, in $\mathrm{s}$;

$z$ is the characteristic dimension, which depends on the shape of the solid, in $\mathrm{m}$,

$D_{\text {ef }}$ represents the effective diffusion coefficient during the rehydration of the solid, in $\mathrm{m}^{2} \mathrm{~s}^{-1}$.

For long drying periods, and in this case for rehydration, the series represented by [eq. (2)] converges quickly. Thus, it is possible to calculate the diffusion coefficient graphically from the linearization of the first term of the series represented by [eq. (3)], as proposed by Ismail et al. (2017) when evaluating sun drying of green 
bean and similarly to that proposed by Aral \& Beșe (2016) when evaluating the drying kinetics of hawthorn fruit.

$$
\begin{aligned}
& R X=\frac{\overline{X_{t}}-X_{e q}}{X_{0}-X_{e q}}=\frac{6}{\pi^{2}} \sum_{n=1}^{\infty} \frac{1}{n^{2}} e^{\left(\frac{-n^{2} \pi^{2} D_{e f} t}{\psi^{2} R_{e q}^{2}}\right)} \\
& R X=\frac{6}{\pi^{2}} e^{\left(\frac{-\pi^{2} D_{e f} t}{\psi^{2} R_{e q}^{2}}\right)}
\end{aligned}
$$

in which:

$R X$ represents the moisture ratio, dimensionless;

$\overline{X_{t}}$ is the instantaneous moisture content, in each time interval, on a dry basis (d.b.);

$X_{e q}$ is the equilibrium moisture content after a certain drying/rehydration time, in d.b.;

$X_{0}$ is the initial moisture of the solid, in d.b.;

$R_{e q}$ is the equivalent radius, calculated according to Falade \& Abbo (2007) and Hebbar \& Rastogi (2001), in cm;

$\psi$ is the sphericity;

$t$ is time, in $\mathrm{s}$,

$D_{e f}$ is the effective diffusion coefficient of water during the rehydration of the berries, in $\mathrm{cm}^{2} \mathrm{~s}^{-1}$.

The equivalent radius was calculated according to Falade \& Abbo (2007) and Hebbar \& Rastogi (2001) as follows:

$$
R_{s}=\frac{3 V}{S_{p}}=\left(\frac{3 V}{S_{s}}\right)\left(\frac{S_{s}}{S_{p}}\right)=\psi R_{e q}
$$

$$
\begin{aligned}
& V=\left(\frac{4}{3}\right) \pi a^{2} b \\
& S_{p}=2 \pi a^{2}+\left(\frac{\pi b^{2}}{e}\right) \ln \left(\frac{1+e}{1-e}\right) \\
& e=\left[1-\left(\frac{b}{a}\right)^{2}\right]^{1 / 2}
\end{aligned}
$$

$$
\psi=\left(\frac{S_{s}}{S_{p}}\right)
$$

in which:

$V$ and $S_{p}$ are the volume and the surface area of the berries, respectively;

$S_{s}$ is the surface area of a sphere with a volume equal to that of the sample;

$\psi$ is the shape factor,

$R s$ is the radius of the sphere;

$R_{e q}$ is the equivalent radius of the berries;

$a$ and $b$ are, respectively, major and minor semi-axes of the rotating ellipse,

$e$ is eccentricity.

Six empirical and semi-empirical models used to describe drying operations were tested, in addition to Fick's law, to describe the rehydration of berries. Therefore, it was considered that, in both operations, mass transfer occurs by diffusion of water inside the fruits. These models are shown in Table 1.

TABLE 1. Mathematical models used to predict food rehydration.

\begin{tabular}{cc}
\hline Model & \\
\hline Verma & $R X=a e^{-k t}+(1-a) e^{-k_{1} t}$ \\
Page & $R X=e^{-k t^{n}}$ \\
Newton & $R X=e^{-k t}$ \\
Henderson and Pabis & $R X=a e^{-k t}$ \\
Two-term exponential & $R X=a e^{-k t}+(1-a) e^{-k a t}$ \\
Diffusion approximation model & $R X=a e^{-k t}+(1-a) e^{-k b t}$
\end{tabular}

Where: $R X$ is the moisture ratio, dimensionless; $k, k_{l}$ are drying constants, in $\mathrm{t}^{-1} ; a, b, c, n$ are coefficients of the models, dimensionless; $t$ is the drying time, in s; $D_{e f}$ is the effective diffusion coefficient of water or milk during the rehydration of berries, in $\mathrm{cm}^{2} \cdot \mathrm{s}^{-1}$.

Source: Adapted from Aral \& Beșe (2016). 


\section{Statistical assessments}

To test for significant differences among the physicochemical characteristics assessed, analysis of variance (ANOVA) and Tukey's test at the 5\% level of significance were performed.

The parameters of the rehydration models (Eqs. 9 to 14) were obtained by non-linear regression using a statistical software program that uses the least-squares method (Gauss-Newton) to fit the experimental data, using a convergence criterion of $1 \cdot 10^{-6}$. Fick's law was fitted to the experimental data through the linearization of Eq. 3.

To verify the fit of the experimental data to the models, the magnitude of the coefficient of determination $\left(R^{2}\right)$, the root mean square error $(R M S E)$, and the values of the relative mean error $(P)$ were assessed, the latter calculated according to eqs (15) and (16), respectively.

$$
R M S E=\sqrt{\frac{\sum_{i=1}^{N}\left(x_{\text {calc }}-x_{\text {exp }}\right)^{2}}{n}}
$$

$$
P=\frac{100}{n} \sum_{i=1}^{N} \frac{\left|x_{\text {exp }}-x_{\text {calc }}\right|}{x_{\text {exp }}}
$$

in which:

$x_{\text {exp }}$ is the experimental value;

$x_{\text {calc }}$ is the value predicted by the model,

$n$ is the number of experimental observations.

According to Rudy et al. (2015), low values of RMSE and $R^{2}$ close to 1.0 denote a good fit of the experimental data to the models. According to Krokida \& Marinos-Kouris (2003), the relative mean error indicates the relative error of the predictions, and values below $10 \%$ are indicative of a reasonable fit for more practical purposes.

\section{RESULTS AND DISCUSSION}

\section{Physicochemical characteristics of the berries}

Table 2 shows the physicochemical characteristics of the berries before and after rehydration at $29^{\circ} \mathrm{C}$ for $45 \mathrm{~min}$.

TABLE 2. Physicochemical characteristics of dehydrated and rehydrated berries in water and milk at $29^{\circ} \mathrm{C}$ for $45 \mathrm{~min}$.

\begin{tabular}{ccccc}
\hline & Moisture (\%) & Ash (\%) & aw & Proteins (\%) \\
\hline & \multicolumn{3}{c}{ Cranberries } \\
\hline Dehydrated & $19.98 \pm 0.40^{\mathrm{a}}$ & $0.24 \pm 0.03^{\mathrm{a}}$ & $0.5962 \pm 0.0174^{\mathrm{a}}$ & $0.37 \pm 0.04^{\mathrm{a}}$ \\
Rehydrated in water & $29.20 \pm 0.87^{\mathrm{a}}$ & $0.21 \pm 0.02^{\mathrm{a} . \mathrm{b}}$ & $0.9050 \pm 0.0322^{\mathrm{b}}$ & $0.31 \pm 0.10^{\mathrm{a}}$ \\
Rehydrated in milk & $26.33 \pm 0.27^{\mathrm{a}}$ & $0.29 \pm 0.01^{\mathrm{a} . \mathrm{b}}$ & $0.8251 \pm 0.0850^{\mathrm{b}}$ & $0.65 \pm 0.1^{\mathrm{b}}$ \\
\hline & Blueberries & \\
\hline Dehydrated & $16.78 \pm 0.45^{\mathrm{c}}$ & $0.23 \pm 0.03^{\mathrm{b}}$ & $0.6072 \pm 0.0089^{\mathrm{b}}$ & $1.84 \pm 0.32^{\mathrm{b}}$ \\
Rehydrated in water & $47.33 \pm 0.09^{\mathrm{a}}$ & $0.12 \pm 0.04^{\mathrm{b}}$ & $0.9678 \pm 0.0090^{\mathrm{a}}$ & $1.56 \pm 0.15^{\mathrm{b}}$ \\
Rehydrated in milk & $35.24 \pm 0.95^{\mathrm{b}}$ & $0.59 \pm 0.16^{\mathrm{a}}$ & $0.9373 \pm 0.0240^{\mathrm{a}}$ & $2.64 \pm 0.07^{\mathrm{a}}$ \\
\hline
\end{tabular}

Results expressed as average \pm standard error. Lowercase letters superscript in the same column for the same fruit indicate a statistical difference according to Tukey's test $(\mathrm{p}<0.05)$.

Moisture and water activity of the dehydrated berries showed reduced values, which was expected because they were subjected to the drying operation.

The ash content of dehydrated berries was similar to that found in blueberries by Silveira et al. (2007): $0.19 \pm$ $0.01 \%$. On the other hand, the protein content was lower than that verified by the authors $(0.57 \pm 0.04 \%)$. Furthermore, the protein content of the blueberries used in rehydration tests was much higher than that of cranberries and blueberries assessed by Silveira et al. (2007).

After rehydration, there was a significant increase in the moisture and water activity of the fruits, as expected. Also, it was found that the protein and ash contents of the fruits rehydrated in milk were significantly higher than those determined in dehydrated fruits and those rehydrated in water, indicating the diffusion of other compounds present in milk, such as minerals and amino acids, into the fruit. The berries rehydrated in water, on the other hand, showed a reduction in the abovementioned contents, albeit nonsignificant, possibly due to leaching from the fruits during rehydration as a result of diffusion of the components present in the cellular tissue of the berries into the water.

\section{Diffusion coefficients}

The diffusion coefficients of water and milk during the rehydration of blueberries and cranberries, calculated from the linearization of Eq. 3, and the statistical parameters used to verify the fit of the experimental data to Fick's law are shown in Table 3. 
TABLE 3. Diffusion coefficients of water and milk during the rehydration of berries at different temperatures and statistical parameters used to assess the fit of experimental data to the model.

\begin{tabular}{cccccc}
\hline & $\boldsymbol{T}\left({ }^{\mathbf{C}}\right)$ & $\boldsymbol{D}_{\text {ef }}\left(\mathbf{c m}^{\mathbf{2}} \mathbf{s}^{-1}\right)$ & $\boldsymbol{R}^{2}$ & $\boldsymbol{P}(\boldsymbol{\%})$ & $\boldsymbol{R M S E}$ \\
\hline & & Cranberries & & & \\
\hline \multirow{2}{*}{ Water } & 7 & $8.33 \cdot 10^{-5} \pm 7.70 \cdot 10^{-6 \mathrm{~b}}$ & 0.94 & 23.49 & 0.24 \\
& 29 & $9.35 \cdot 10^{-5} \pm 1.63 \cdot 10^{-5 \mathrm{~b}}$ & 0.96 & 23.26 & 0.24 \\
& 45 & $1.25 \cdot 10^{-4} \pm 2.23 \cdot 10^{-5} \mathrm{a}$ & 0.96 & 20.87 & 0.23 \\
\hline Milk & 7 & $1.21 \cdot 10^{-4} \pm 8.42 \cdot 10^{-6 \mathrm{a}}$ & 0.92 & 23.19 & 0.24 \\
& 29 & $1.50 \cdot 10^{-4} \pm 3.39 \cdot 10^{-5} \mathrm{a}$ & 0.97 & 20.00 & 0.23 \\
\hline \multirow{2}{*}{ Water } & 7 & Blueberries & & & \\
& 29 & $3.08 \cdot 10^{-8} \pm 3.97 \cdot 10^{-9} \mathrm{a}$ & 0.93 & 38.54 & 0.33 \\
& 45 & $3.57 \cdot 10^{-8} \pm 2.78 \cdot 10^{-9} \mathrm{a}$ & 0.85 & 38.83 & 0.32 \\
& 7 & $3.64 \cdot 10^{-8} \pm 1.08 \cdot 10^{-9} \mathrm{a}$ & 0.83 & 41.06 & 0.32 \\
\hline \multirow{2}{*}{ Milk } & $3.65 \cdot 10^{-8} \pm 3.79 \cdot 10^{-9} \mathrm{a}$ & 0.75 & 41.25 & 0.33 \\
& 29 & $2.51 \cdot 10^{-8} \pm 8.86 \cdot 10^{-10 \mathrm{~b}}$ & 0.84 & 38.2 & 0.3 \\
\hline
\end{tabular}

Results are expressed as mean \pm standard error. Lowercase superscript letters in the same column for the same fruit indicate a statistically significant difference according to Tukey's test $(\mathrm{p}<0.05)$.

The diffusion of both water and milk was influenced by temperature, increasing as temperature increased. During the rehydration of cranberries in water, there was no significant difference between the diffusion coefficients at 7 and $29^{\circ} \mathrm{C}$. However, they were both significantly lower than the diffusion coefficient at $45^{\circ} \mathrm{C}$. In milk, there was an increase in the value of diffusivity with temperature, although the difference was not significant. At the lowest process temperature, the diffusion coefficients in milk were greater than those in water. However, at $29^{\circ} \mathrm{C}$, the diffusivities of water were greater than those of milk. This observation requires further confirmation. However, as verified in the analysis of the ash and protein contents, when the fruit was rehydrated with milk, not only water but also other nutrients diffused into the fruit, and these different diffusive flows may have influenced, positively or not, the diffusion of the solvent (milk).

It was found that Fick's law reasonably fit the experimental data, as the coefficient of determinations $\left(R^{2}\right)$ were greater than 0.75 , the $P$ values greater than $10 \%$, and the $R M S E$ was close to zero.

Falade \& Abbo (2007), when assessing the dependence of the effective diffusion coefficient on temperature during drying and rehydration of three different date cultivars, found that the effective diffusion coefficients $\left(D_{e f}\right)$ ranged from $1.8 \cdot 10^{-10}$ to $1.15 \cdot 10^{-9} \mathrm{~m}^{2} \mathrm{~s}^{-1}$ (soft red), $2.69 \cdot 10^{-10}$ to $9.51 \cdot 10^{-10} \mathrm{~m}^{2} \mathrm{~s}^{-1}$ (Time 2), and $4.27 \cdot 10^{-10}$ to $1.41 \cdot 10^{-9} \mathrm{~m}^{2} \mathrm{~s}^{-1}$ (Time 3) when the water rehydration process was carried out in the temperature range between 15 and $45^{\circ} \mathrm{C}$. The authors observed an increase in the effective diffusion coefficient with increasing process temperature, as seen in the present study. The diffusivities calculated by Falade \& Abbo (2007) were lower than those determined in the present work. However, it must be considered that those authors dehydrated the fruits themselves, controlling the process parameters properly. In the present study, the fruits were purchased from a local market and they had already been dried.

\section{Modeling of rehydration from empirical/ semi-empirical models}

For the rehydration of cranberries in water, the fit to all the tested empirical or semi-empirical models showed high correlation coefficients, $R^{2}>0.95, P$ values below $10 \%$, and low $R M S E$ values, which indicates a good data fit. On the other hand, the fit of the experimental data for the rehydration of dehydrated blueberries in water to the proposed models was less than ideal since the $R^{2}$ values were less than 0.90 and the $P$ values greater than $10 \%$.

For the rehydration of cranberries in water at $7^{\circ} \mathrm{C}$, the Page model ( $R X=e^{-0.0022 t^{0.7588}}$ ) was the one that best fit the experimental data because it presented $R^{2}=0.98$ and the lowest values of $P$ and $R M S E$. At $29^{\circ} \mathrm{C}$, the diffusion approximation model

$\left.R X=-0.0153 e^{-0.5222 t}+(1+0.0153) e^{-0.0006 t}\right]$ was the one that best represented the experimental data, as it presented the highest correlation coefficients $\left(R^{2}=0.99\right)$ and the lowest values of $P$ and $R M S E$. For the experiments carried out in the water at $45^{\circ} \mathrm{C}$, the Verma [ $\left.R X=0.9996 e^{-0.0009 t}+(1-0.9996) e^{0.0134 t}\right] \quad$ and diffusion approximation $\left.R X=0.9997 e^{-0.0009 t}+(1-0.9997) e^{0.0134 t}\right]$ models presented the best fit, with $R^{2}$ values equal to 0.99 and $P$ less than $1 \%$.

For the rehydration of blueberries in water, the diffusion approximation model was the one that best represented the experimental data at temperatures of $7^{\circ} \mathrm{C}$ 
$\left[R X=0.9706 e^{-0.0021 t}+(1-0.9706) e^{0.0057 t}\right] \quad$ and $29^{\circ} \mathrm{C} \quad\left[R X=0.9981 e^{-0.0022 t}+(1-0.99817) e^{0.0139 t}\right]$, presenting $R^{2}>0.96, P$ values below $4 \%$, and RMSE close to zero. For the experiment conducted at $45^{\circ} \mathrm{C}$, the experimental data showed the best fit to the Verma $\left[R X=0.0437 e^{0.0060 t}+(1-0.0437) e^{-0.0033 t}\right] \quad$ and diffusion approximation [ $\left.R X=0.9563 e^{-0.0033 t}+(1-0.9563) e^{0.0060 t}\right]$ models, with the highest values of the coefficient of determination and the lowest of $P$ and $R M S E$.

In the rehydration tests of cranberries in milk, it was found that all models had correlation coefficients $\left(R^{2}\right)$ greater than $0.90, P$ values lower than $10 \%$, and low $R M S E$ values, indicating a good fit to the experimental data. The same was not observed for the rehydration of blueberries in milk, as some models had $R^{2}$ less than 0.90 and $P$ values greater than $10 \%$.

For the temperature of $7^{\circ} \mathrm{C}$, the diffusion approximation model $\left[R X=-0.0427 e^{-0.2445 t}+(1-0.0427) e^{-0.0005 t}\right]$ was the one that best represented the experimental data of rehydration of cranberries in milk, with $R^{2}=0.99$ and low values of $P$ and $R M S E$. At $29^{\circ} \mathrm{C}$, experimental data on rehydration in milk were a better fit to the Verma model $\left[R X=-6.6195 e^{0.0006 t}+(1+6.6195) e^{0.0004 t}\right]$, due to presenting the highest correlation coefficient $\left(R^{2}=0.99\right)$ and the lowest $P$ and $R M S E$ values. The rehydration of blueberries at a refrigerated temperature was best represented by the Page model $\left(R X=e^{-0.0130 t^{0.649}}\right)$ because the $P$ and $R M S E$ values were the lowest among all the models considered, even though the value of the coefficient of determination was lower than $0.90\left(R^{2}=\right.$ 0.88 ). At $29^{\circ} \mathrm{C}$, the experimental data on the rehydration of blueberries in milk were a better fit to the Verma model [ $\left.R X=0.0265 e^{-0.7223 t}+(1-0.0265) e^{-0.0011 t}\right]$, with $R^{2}$ $=0.99, P=1.76 \%$ and $R M S E=0.02$.

No studies on the rehydration of dehydrated foods using empirical and semi-empirical models to describe the rehydration process, as performed in the present study, were found in the literature. However, considering the phenomenon of mass transfer by diffusion, the modeling mentioned above was considered relevant. Therefore, it was not possible to compare the fit of the rehydration data to the empirical/semi-empirical models with other works in the literature.

However, Rudy et al. (2015) used the Newton, Page, Henderson and Pabis, logarithmic, Wang and Singh, and two-term exponential models to represent the drying kinetics of cranberries. They found that the drying data for whole fruits were a better fit to the logarithmic model and that the models by Wang and Singh and Page were the ones that best represented the drying data for fruit pulp.

It is also important to emphasize that these are empirical models used to predict the moisture content of the samples in a certain period. However, the models presented in Table 1 do not provide information related to the diffusion of the species.

\section{CONCLUSIONS}

Rehydration presented itself as a promising alternative for the enrichment of dehydrated foods when solvents rich in nutrients are used in the process as the rehydration of berries in milk resulted in nutrient gains as a consequence of the different diffusive flows that occur during the process. In this sense, the authors believe that additional studies should be conducted on rehydration using milk to investigate the diffusion of not only water but also other nutrients from milk to fruits. Fick's law satisfactorily represented the rehydration of dehydrated fruits, making it possible to calculate the diffusion coefficients of water and milk. These data are essential for the design/construction of equipment, and/or the optimization and implementation of processes. The rehydration of dehydrated cranberries and blueberries showed a good fit to the empirical/semiempirical models usually used to describe food drying. These data are of interest as the calculation of the operating time can be performed based on the abovementioned models, which enable flexibility as they are mathematically simpler than Fick's law.

\section{ACKNOWLEDGMENTS}

The authors would like to thank the Federal University of Technology - Paraná for financial and technological support.

\section{REFERENCES}

Alvarez-Suarez JM, Giampieri F, Cordero M, Gasparrini M, Forbes-Hernández TY, Mazzoni L, Afrin S, BeltránAyala P, González-Paramás AM, Santos-Buelga C, Varela-Lopez A, Quiles JL, Battino M (2016) Activation of AMPK/Nrf2 signalling by Manuka honey protects human dermal fibroblasts against oxidative damage by improving antioxidant response and mitochondrial function promoting wound healing. Journal of Functional Foods 25:38-49.

AOAC - Association of Official Analytical Chemists (2005) Official methods of analysis. Arlington, AOAC International, 18 ed.

Aral S, Beșe AV (2016) Convective drying of hawthorn fruit (Crataegus spp.): Effect of experimental parameters on drying kinetics, color, shrinkage, and rehydration capacity. Food Chemistry 210(1): 577-584.

Ballesteros LF, Ramirez MJ, Orrego CE, Teixeira JA, Mussatto SI (2017) Encapsulation of antioxidant phenolic compounds extracted from spent coffee grounds by freezedrying and spray-drying using different coating materials. Food Chemistry 237:623-631.

Demiray E, Tulek Y (2017) Effect of temperature on water diffusion during rehydration of sun-dried red pepper (Capsicum annuиm L.). Heat and Mass Transfer 53:18291834.

Falade OK, Abbo SE (2007) Air-drying and rehydration characteristics of date palm (Phoenix dactylifera $\mathrm{L}$.) fruits. Journal of Food Engineering 79(2):724-730. 
FAOSTAT - Statistics from Food and Agriculture Organization of the United Nations (2020). Available: http://www.fao.org/faostat/en/\#data/QC/visualize. Accessed Apr 01, 2020.

Gökçe Kocabay Ö, İsmail O (2017) Investigation of rehydration kinetics of open-sun dried okra samples. Heat and Mass Transfer 53:2155-2163.

Gramza-Michałowska A, Sidor A, Kulczynski B (2017) Berries as a potential anti-influenza factor - A review. Journal of Functional Foods 37:116-137.

Hebbar HU, Rastogi NK (2001). Mass transfer during infrared drying of cashew kernel. Journal of Food Engineering 47(1):1-5.

Ho KKHY, Ferruzzi MG, Wightman JD (2020) Potential health benefits of (poly)phenols derived from fruit and 100\% fruit juice. Nutrition Reviews 78(2):145-174.

Ismail O, Figen AK, Pişkin S (2017) Open sun drying of green bean: influence of pretreatments on drying kinetics, colour and rehydration capacity. Heat and Mass Transfer 53:1277-1288.
Krokida MK, Marinos-Kouris D (2003) Rehydration kinetics of dehydrated products. Journal of Food Engineering 57(1):1-7.

Lee KT, Farid M, Nguang S (2006) The mathematical modelling of the rehydration characteristics of fruits. Journal of Food Engineering 72(1):16-23.

Lewicki PP (1998) Some remarks on rehydration of dried foods. Journal of Food Engineering 36(1):81-87.

Oszmiański J, Kolniak-Ostek J, Lachowicz S, Gorzelany J, Matłok N (2015) Effect of dried powder preparation process on polyphenolic content and antioxidant capacity of cranberry (Vaccinium macrocarpon L.). Industrial Crops and Products 77:658-665.

Rudy S, Dziki D, Krzykowski A, Gawlik-Dziki U, Polak R, Rózylo R, Kulig R (2015) Influence of pre-treatments and freeze-drying temperature on the process kinetics and selected physico-chemical properties of cranberries (Vaccinium macrocarpon Ait.). LWT-Food Science and Technology 63(1):497-503.

Silveira NGA, Vargas PN, Rosa CS (2007) Teor de polifenóis e composição química do mirtilo do grupo Highbush. Alimentos e Nutrição 18(4):365-370. 